\title{
Risk factors for asthma in young adults
}

\author{
J. Sunyer*, J.M. Antó*, M. Kogevinas*, M.A. Barceló*, J.B. Soriano*, A. Tobías*, \\ N. Muniozguren**, J. Martínez-Moratalla+, F. Payo+, J.A. Maldonado", \\ the Spanish Group of the European Community Respiratory Health Survey
}

Risk factors for asthma in young adults. J. Sunyer, J.M. Antó, M. Kogevinas, M.A. Barceló, J.B. Soriano, A. Tobías, N. Muniozguren, J. Martínez-Moratalla, F. Payo, J.A. Maldonado, the Spanish Group of the European Community Respiratory Health Survey. (C) ERS Journals Ltd 1997.

ABSTRACT: We assessed the association of asthma prevalence in young adults with susceptibility factors and environmental exposures, taking into account the age at asthma onset.

A random sample of the general population, aged 20-44 yrs, in five areas of Spain (Albacete, Barcelona, Galdakao, Huelva, and Oviedo) was selected in the frame of the European Community Respiratory Health Survey (ECRHS). Overall, $\mathbf{2 , 6 4 6}$ subjects (response rate $\mathbf{6 0 0 . 9 \%}$ ) responded to a respiratory questionnaire and $1,797(41.4 \%)$ finalized a bronchial challenge.

Atopy to perennial (odds ratio $(\mathrm{OR})=\mathbf{1 0 . 2}, 95 \%$ confidence interval 4.2-25) and seasonal allergens $(11.5,4.6-28)$, parental asthma $(4.5,2.5-8.4)$, and birth order (OR for no older siblings in comparison to having more than two $=3.2$, 1.2-9.1) were associated with current asthma whatever the age of asthma onset. Past asthma was associated to a lesser extent with atopy (OR around 3.5 to both perennial and seasonal allergens). Lower respiratory tract infections before the age of 5 yrs (LRTI), having had a pet in childhood, and being born in a younger cohort were associated with asthma starting before the age of $15 \mathrm{yrs}$, but not after. Male gender was more frequent in childhood asthma and female gender in adulthood.

In addition to the known risk factors of asthma (atopy to perennial allergens, parental asthma) we provide evidence for an association of asthma (whatever the age of onset) with sensitization to seasonal allergens, and having less than three older siblings; and for an association of childhood asthma with lower respiratory tract infections.

Eur Respir J 1997; 10: 2490-2494.

The role of many risk factors involved in the onset of asthma and exacerbation remains, in part, controversial. The production of specific immunoglobulin $\mathrm{E}$ (IgE) antibodies in response to environmental allergens (atopy) has been strongly associated with asthma [1]. Allergen exposure in sensitized children is known to initiate an immediate and late cellular airway reaction and bronchial obstruction [2]. However, though asthma is strongly associated with atopy, it only occurs in a proportion of atopics [3]. It is unclear to what extent asthma relates to the type of allergen (due to a different potency, such as the supposed supremacy of Dermatophagoides pteronyssinus $[4,5])$ rather than to the level of allergen in the environment (as occurred in places without $D$. pteronyssinus [6]). In addition, viral infections in early life may protect [7] or, in contrast, enhance [8] the sensitization process. In adulthood, high exposures to new allergens, such as occupational allergens [9], may mimic the sensitization process occurring in early life. Other factors in adulthood, such as exposure to irritants [10] have been proposed as contributors to the persistence of asthma at that age.

Asthma is a chronic episodic disease initiated in childhood in many subjects [11]. Although the overall fea-
*Unitat de Recerca Respiratòria i Ambiental, Institut Municipal d'Investigació Mèdica (IMIM), Barcelona. **Dept of Epidemiology, Dirección de Salud de Vizcaya, Bilbao. +Dept of Pneumology, Hospital General de Albacete. ${ }^{++}$Instituto Nacional de Silicosis, Oviedo. ${ }^{\star H o s p i t a l}$ General de Huelva, Spain.

Correspondence: J. Sunyer, Unitat de Recerca Respiratòria i Ambiental, Institut Municipal d'Investigació Mèdica (IMIM), Doctor Aiguader 80, E-8003 Barcelona, Spain.

Keywords: Asthma bronchial responsiveness risk factors

Received: November 211996 Accepted after revision July 51997

This study was supported in part by grants from Fondo Investigaciones Sanitarias, Madrid, Spain (FIS, no. 93/0393), and Generalitat de Catalunya (CIRIT/GRQ95-9304). tures of asthma are similar in children and adults, there are numerous distinctions [12]. Thus, the study of risk factors involved in asthma onset and exacerbation requires a temporal perspective that only large follow-up studies can provide. A cheaper, but less valid approach is to use retrospective information provided by crosssectional studies carried out in adulthood.

We assessed the association of susceptibility factors, environmental exposures in childhood and adulthood with asthma prevalence, at ages ranging 20-44 yrs, in a community-based sample in Spain, taking into account the age of asthma onset. The study forms part of the European Community Respiratory Health survey (ECRHS) [13]. Occupational exposures are not examined in this paper since they refer to specific segments of the population rather than to the general population. Exposures to irritants and maternal smoking were not assessed due to limits in the statistical power of the study.

\section{Methods}

A sample of 16,884 subjects, aged 20-44 yrs, was randomly selected from the general population of five areas in Spain (Albacete, Barcelona, Galdakao, Huelva, 
and Oviedo). A short and simple screening respiratory questionnaire was administered by mail and telephone to $85 \%$ of the subjects. In a second phase, a random subsample of 3,310 subjects from the original sample $(\sim 20 \%)$ was selected. In addition, 1,029 individuals (symptoms subsample) who reported "symptoms related with asthma" in the short respiratory interview, but who were not included in the random subsample, were also invited to take part in this second phase of the study. From March 1992 to April 1993, subjects were invited to attend a centre in each city. The ECRHS respiratory questionnaire [13] on respiratory symptoms and environmental risk factors was completed, in addition to a basic spirometry, a dose-response methacholine challenge test, and total and specific serum $\operatorname{IgE}$ responses to pets, pollen and mould levels. All the tests were performed during the same visit. From the 4,339 individuals, 2,646 (60.9\%) responded to the ECRHS respiratory questionnaire on symptoms and risk factors and 1,797 $(41.4 \%)$ completed a bronchial responsiveness challenge. Cases were derived from both the random and the symptoms subsamples. Controls were derived exclusively from the random subsample. Subjects from the symptoms subsample who did not correspond to the definition of a case were excluded. The Institutional Review Board of the participating centres approved the study protocol and patients gave written informed consent.

We classified asthma (that is a report of "ever having had asthma") according to the age of onset before or after 15 yrs of age. This cut-off point was based on clinical significance and also statistical criteria (since 15 yrs is the median age of onset in this population). Secondly, asthma was divided into current or past according to a report of an attack of asthma during the last 12 months. "Current asthma" could also be envisaged as a more specific definition since it appears strongly associated with concurrent measurements of pulmonary function or nonspecific airway responsiveness [14]. To increase the specificity in the definition [15] we used a second definition incorporating bronchial responsiveness. Subjects who reported ever having had asthma and showed bronchial hyperresponsiveness, were classified as cases.

Bronchial hyperresponsiveness was measured through a methacholine inhalation challenge test [13]. Bronchial responsiveness was defined as a fall in forced expiratory volume in one second (FEV1) by $\geq 20 \%$ of the value following saline inhalation at a maximum concentration of methacholine of $100 \mathrm{mg} \cdot \mathrm{mL}^{-1}$ (i.e., 5.117 $\mathrm{mmol}$ ) or extrapolated to $8 \mathrm{mmol}$. Thus, bronchial hyperresponsiveness was expressed as a dichotomous variable: presence or absence of a fall in FEV1.

Atopy was assessed by means of serum-specific $\operatorname{IgE}$ response (capsulated hydrophilic carrier polymer (CAP) method) in a central lab and skin sensitivity tests following a standard procedure [13]. A subject was considered atopic if any of the responses to indoor allergens (cat dander, Cladosporium, D. pteronyssinus) and outdoor allergens (Alternaria, birch, olive, Parietaria, ragweed, timothy grass) were positive (i.e., a skin response $>3 \mathrm{~mm}$ or a CAP $>0.35 \mathrm{kU} \cdot \mathrm{L}^{-1}$ ) [13]. Nonatopy was a negative response to all the antigens.

The association of asthma symptoms and bronchial hyperresponsiveness with the risk factors, was calcu- lated by the odds ratio (OR) using standard methods of logistic regression analysis [16]. Subjects without symptoms of asthma or asthma and bronchial hyperresponsiveness were taken as the control group. Variables that modified the association of a given risk factor with asthma symptoms were estimated by testing the significance of interactions in the logistic regression model. A pvalue of 0.05 was defined as representing statistical significance.

\section{Results}

The sociodemographic characteristics of subjects in the study according to the classifications used to define asthma (area, sex and age) is shown in table 1. Participants in the bronchial challenge test differed significantly for area and sex compared to those who were only interviewed.

Table 1. - Social-demographic characteristics of subjects in the study according to instrument used to define asthma

\begin{tabular}{|c|c|c|c|c|c|}
\hline & \multicolumn{2}{|c|}{ Questionnaire } & \multicolumn{2}{|c|}{$\begin{array}{c}\text { Bronchial } \\
\text { challenge test }\end{array}$} \\
\hline & & $\mathrm{n}$ & $\%$ & $\mathrm{n}$ & $\%$ \\
\hline \multirow[t]{4}{*}{ Asthma } & No & 1861 & 88.8 & $1068^{\#}$ & 92.4 \\
\hline & Ever & 234 & 11.2 & 88 & 7.6 \\
\hline & Current & 107 & 5.1 & & \\
\hline & Past & 127 & 6.1 & & \\
\hline \multirow[t]{5}{*}{ Area* } & Barcelona & 435 & 20.7 & 163 & 14.1 \\
\hline & Galdakao & 523 & 25.0 & 335 & 29.0 \\
\hline & Albacete & 473 & 22.6 & 254 & 22.0 \\
\hline & Oviedo & 383 & 18.3 & 213 & 18.4 \\
\hline & Huelva & 281 & 13.4 & 191 & 16.4 \\
\hline \multirow[t]{5}{*}{ Age } & $20-24$ & 431 & 20.5 & 260 & 22.5 \\
\hline & $25-29$ & 420 & 20.0 & 232 & 20.1 \\
\hline & $30-34$ & 414 & 19.8 & 226 & 19.6 \\
\hline & $35-39$ & 415 & 19.8 & 228 & 19.8 \\
\hline & $40-44$ & 415 & 19.8 & 210 & 18.2 \\
\hline \multirow[t]{2}{*}{ Sex* } & Female & 1096 & 52.3 & 549 & 47.5 \\
\hline & Male & 999 & 47.7 & 607 & 52.5 \\
\hline All & & 2095 & 100 & 1156 & 100 \\
\hline
\end{tabular}

n: number of subjects. *: statistically significant $(\mathrm{p}<0.05)$ differences were present in the distribution by area and sex between all subjects and those completing bronchial challenge test. \#: number of subjects who reported neither ever asthma nor bronchial responsiveness, whereas ever refers to presence of both conditions.

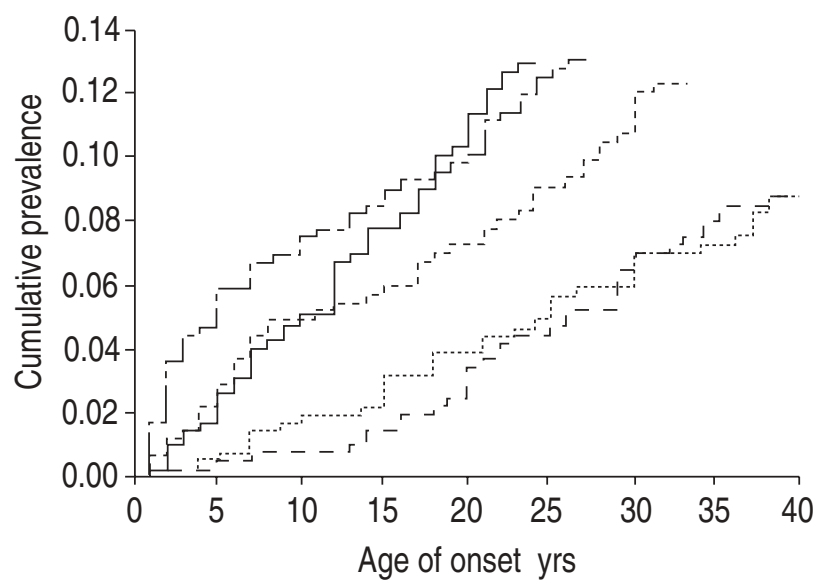

Fig. 1. - Cumulative prevalence of asthma by age of onset and cohort of birth (each year signals the middle of a $5 \mathrm{yr}$ period). - - -: 1950 cohort; -----: 1955; -.--_-.: 1960; - - 1965 ; — 1970. 
Table 2. - Prevalence of asthma by risk factors, and crude odds ratio (OR) and 95\% confidence interval (95\% Cl)

\begin{tabular}{|c|c|c|c|c|c|c|c|c|c|}
\hline & & \multicolumn{8}{|c|}{ Age of onset } \\
\hline & & \multicolumn{4}{|c|}{$\leq 15 \mathrm{yrs}$} & \multicolumn{4}{|c|}{$>15 \mathrm{yrs}$} \\
\hline & & \multicolumn{2}{|r|}{$\begin{array}{l}\text { Current asthma } \\
(39 / 1861)^{\#}\end{array}$} & \multicolumn{2}{|r|}{$\begin{array}{l}\text { Past asthma } \\
(78 / 1861)^{\#}\end{array}$} & \multicolumn{2}{|r|}{$\begin{array}{l}\text { Current asthma } \\
(68 / 1861)^{\#}\end{array}$} & \multicolumn{2}{|r|}{$\begin{array}{l}\text { Past asthma } \\
(49 / 1861)^{\#}\end{array}$} \\
\hline & & $\%$ & OR $(95 \% \mathrm{CI})$ & $\%$ & OR $(95 \% \mathrm{CI})$ & $\%$ & OR $(95 \% \mathrm{CI})$ & $\%$ & OR $(95 \% \mathrm{CI})$ \\
\hline \multicolumn{10}{|c|}{ Susceptibility factors } \\
\hline Sex & Female & 1.3 & $-0.49)^{*}$ & 3.0 & $0.57(0.36-0.92)^{*}$ & 5.1 & $2.99(1.69-5.28)^{*}$ & 3.2 & 1.7 \\
\hline Parental asthma & & 6.9 & 5.16 & 4.7 & 1.21 & 6.4 & $2-6.70)^{*}$ & 7.4 & 4.01 \\
\hline \multirow{3}{*}{ Atopy } & Indool & 4.2 & $39.6(4.84-324) *$ & 7.1 & $4.84(2.20-10$. & 4.9 & $4.95(1.59-15.3) *$ & 3.7 & $.86-5.92) *$ \\
\hline & Outdoor & 2.4 & $22.2(2.29-215)^{*}$ & 4.0 & $2.64(0.93-7.47)$ & 8.3 & $8.32(2.88-24.2)^{*}$ & 6.2 & $3.95(1.64-9.51)^{*}$ \\
\hline & Both & 9.3 & $91.5(11.6-723)^{*}$ & 16.4 & $12.4(6.04-25.1)^{*}$ & 17.2 & $15.0(6.63-45.5)^{*}$ & 4.3 & $12.4(6.04-25.1)^{*}$ \\
\hline \multicolumn{10}{|c|}{ Exposures in childhood } \\
\hline \multirow[t]{2}{*}{ Older siblings } & $1-2$ & 2.2 & $2.23(0.7$ & 1.3 & $1.35(0.63-2.87)$ & 1.5 & 1.50 & 1.1 & 1.13 \\
\hline & 0 & 1.9 & 1.84 & 1.8 & 1.83 & 1.8 & $1.76(0.85-3.63)$ & 1.0 & $0.94(0.41-2.18)$ \\
\hline LRI & Yes & 11.1 & $9.05(4.46-18.4)^{*}$ & 25.5 & $14.8(9.02-24.2)^{*}$ & 6.2 & $2.16(0.95-4.86)$ & 0.9 & $0.37(0.05-2.73)$ \\
\hline Any animal & Yes & 1.9 & $0.69(0.35-1.37)$ & 3.5 & $0.58(0.36-0.94) *$ & 3.2 & $1.30(0.70-2.39)$ & 2.6 & $1.06(0.53-2.08)$ \\
\hline \multicolumn{10}{|l|}{ Cohort of birth } \\
\hline Year of & $<1958$ & 0.9 & $0.32(0.14-0.73) *$ & 1.7 & $0.29(0.16-0.54) *$ & 3.6 & $1.03(0.63-1.68)$ & 3.7 & $2.13(1.20-3.80)^{*}$ \\
\hline
\end{tabular}

\#: number of cases and controls. *: $\mathrm{p}<0.05$ for comparisons respect to the reference category not shown in table. LRI: lower respiratory tract infection.

Table 3. - Adjusted ${ }^{+}$odds ratio for risk factors and current asthma, asthma with bronchial responsiveness (BR), and past asthma

\begin{tabular}{llccc}
\hline \multicolumn{1}{l}{} & & Current $(60 / 1262)^{\#}$ & Asthma and BR (88/1068)\# & Past asthma $(84 / 1262)^{\#}$ \\
\hline \multirow{2}{*}{ Parental asthma } & & $4.53(2.46-8.36)^{*}$ & $3.13(1.78-5.54)^{*}$ & $2.31(1.31-4.06)^{*}$ \\
Atopy & Indoor & $10.2(4.21-24.6)^{*}$ & $5.39(2.68-10.8)^{*}$ & $3.49(1.31-4.06)^{*}$ \\
& Outdoor & $11.5(4.64-28.5)^{*}$ & $5.88(2.77-12.5)^{*}$ & $3.34(1.68-6.61)^{*}$ \\
& Both & $26.9(11.9-61.1)^{*}$ & $24.1(12.9-45.4)^{*}$ & $7.33(4.09-13.2)^{*}$ \\
Older siblings & $1-2$ & $2.57(0.93-7.09)$ & $2.20(0.96-5.04)$ & $1.30(0.63-2.68)$ \\
& 0 & $3.26(1.16-9.15)^{*}$ & $2.23(0.95-5.27)$ & $1.44(0.68-3.03)$ \\
\hline
\end{tabular}

+: Adjusted for sex, age, area, low respiratory infections $<5 \mathrm{yrs}$, and the rest of variables in the table. Age did not enter in any of the models and lower respiratory tract infections was only included in the model for past asthma, due to $p<0.1$. \#: number of cases and controls in each multivariate model. Due to missing values in atopy, numbers are lower than in table 2. *: $\mathrm{p}<0.05$.

The age of onset of asthma has varied over time. The prevalence of asthma beginning up to the age of $15 \mathrm{yrs}$ was higher in the more recent birth cohorts (fig. 1) although in all birth cohorts there were individuals who reported their asthma had begun after the age of $15 \mathrm{yrs}$.

Factors associated with susceptibility to current asthma beginning up to the age of 15 yrs (table 2) were the male sex, parental asthma, atopy to indoor and outdoor allergens, lower respiratory tract infections (LRTI) before the age $5 \mathrm{yrs}$, and a younger birth cohort. Asthma beginning in childhood but no longer active (past asthma) showed similar associations to risk factors as current asthma. Parental asthma as a risk factor was an exception, as the association with current and past asthma was significantly different. A statistically significant negative association was evident between having had a pet and past asthma.

Current asthma beginning after the age of 15 yrs was significantly associated with only the female sex, parental asthma and atopy (table 2). With the exception of year of birth, risk factors for current and past asthma did not differ. Adjusted associations for the rest of the variables in table 2 were similar to the crude associations shown in table 2, whatever the age of asthma onset.

The association for sex, LRTI, having had a pet and cohort of birth was significantly different in asthma started in childhood compared to adulthood. Table 3 presents the independent association for factors that did not vary with age of onset. The strong association of atopy and parental asthma with current asthma (defined both by questionnaire and bronchial challenge) was confirmed after including all subjects whatever the age of onset. Atopy was associated to a lesser extent with past asthma than with current asthma. Having less than three older siblings was significantly associated with current asthma, suggesting that the lack of statistical significance for this factor observed when stratifying by age of onset was due to lack of statistical power.

\section{Discussion}

In this study of young adults, we assessed the risk factors related with asthma onset occurring early or later in life. Important findings arise from this analysis: firstly; atopy to perennial (indoor) and seasonal (outdoor) allergens, parental asthma, and having less than three older siblings were associated with current asthma whatever the age of asthma onset; secondly, LRTIs before the age of 5 yrs and not having had a pet in childhood were associated with asthma (both current and past) 
starting in childhood but not in adulthood; and finally, the previous factors could not explain the sex differences by ageing and the lowest asthma prevalence in the oldest cohorts.

Case-control studies with prevalent cases are limited when assessing exposures that would have been modified in the past because of disease occurrence, such as indoor environment or having had a pet [17]. A second potential limitation was recall bias. In particular, subjects who have asthma may remember more accurately past episodes of childhood LRTI, such as a past pneumonia, than subjects without asthma. Information bias may also be present in reporting when asthma began, which could be postponed in time by older generations. Nonresponse may have also affected the results of our study. Individuals who did not attend the centre, did not show any difference by sex or age compared with those who participated, but more females with no symptoms declined to participate than females with symptoms. Prevalence of current asthma in females could have been artificially increased. However, our prevalence estimates were similar to those observed using all subjects who participated in the first phase of the ECRHS [18], who were $85 \%$ of the selected, and also to other studies [19]. Adjustment for nonresponse did not result in substantial changes of the prevalence of respiratory symptoms in the ECRHS [20]. Inclusion of bronchial responsiveness in the definition of cases reduces the diagnostic misclassification, but at the cost of increasing nonresponse. In general, our findings for current reported asthma and for reported asthma with bronchial challenge were in substantial concordance.

The strong association of asthma with atopy has been well described previously [21]. We found a strong association with sensitization to seasonal allergens, with a magnitude similar to that for perennial allergens both in current and past asthma. In children, seasonal allergens are believed to be unrelated to asthma [22]. In this study we found a significant association, though we measured atopy in adulthood. Outdoor allergens in adults have been related with epidemic and endemic presentations of emergency room admissions for asthma [23, 24]. This suggests that seasonal allergens might have an important role in asthma during adulthood, as we found in the analysis of the independent association of common aeroallergens with bronchial responsiveness [25]. The association between asthma and atopy was stronger for current asthma than for past asthma. We could not exclude the possibility that the lack of temporal coincidence between measurement of atopy and occurrence of asthma symptoms explained this difference. An alternative explanation for the lower association of atopy with past asthma, and to a lesser extent to parental asthma and family size, is that there was a higher rate of misclassification for past asthma.

LRTI in childhood was associated with a high risk of onset of asthma in childhood, while birth order was inversely associated. Respiratory infections, in particular those leading to bronchiolitis, might be a risk factor for asthma [8]. We performed a retrospective study of LRTI in childhood with a unique question on "important respiratory infections". The lack of specificity of a single question and the possible recall bias weakens the validity of our finding. An inverse association with birth order, explained by a higher frequency of secondary infections in larger families, has been reported previously with wheezing in children [26], coinciding with reports of an association between birth order [27-28] or family size [29] and hay fever. This contradictory pattern may be related to the timing (or the type) of infections in childhood.

We found an inverse association with having had a pet during childhood (whatever the pet, data not shown). Having a pet has been considered a risk factor for asthma attacks [30], but also protective in rural children [31]. Our finding could be due to a self-selection of symptomatic subjects who avoided having a pet.

Gender differences in asthma according to age of onset coincided with previous studies [19]. We cannot exclude, however, the possibility that the higher prevalence in adult women was in part due to a self-selection of nonresponders. An increase of asthma prevalence in younger generations is another relevant finding in this paper. This increase is not explained by variations in atopy, family size, parental asthma, LRTI, or having a pet. Alternative explanations such as changes in the labelling of asthma in recent years or in the vaccination policy could not be ruled out. Recently, changes in the vaccination policy have been postulated as potentially influencing the prevalence of asthma [32]. This information was not available from the ECRHS.

In addition to the known risk factors of asthma (atopy to perennial allergens, parental asthma), we have provided evidence for an association of asthma (whatever the age of onset) with sensitization to seasonal allergens, and having less than three older siblings. There was also an association of childhood asthma with lower respiratory tract infection.

The Spanish Group of the European Community Respiratory Health Survey centres and investigators: J.M. Antó (Principal Investigator); Albacete: J. Martinez-Moratalla, E. Almar, M. Arévalo, A. Mateos, M. Vizcaya; Barcelona: J. Sunyer, F. Burgos, J. Castellsagué, M. Kogevinas, J. Roca, J.B. Soriano, A. Tobías; Galdakao: N. Muniozguren, M. Errazola, A. Capelastegui, J. Ramos; Huelva: J.A. Maldonado, J.L. Sánchez, A. Pereira, J. Gravalos; and Oviedo: R. Quirós, J. Azofra, L. Palenciano, F. Payo, G. Rego, A. Vega.

\section{References}

1. Peat JK, Woolcock AJ. Sensitivity to common allergens: relation to respiratory symptoms and bronchial responsiveness in children from three climatic areas of Australia. Clin Exp Allergy 1991; 21: 573-581.

2. Holgate ST, Kay AB. Mast cells, mediators and asthma. Clin Allergy 1985; 15: 221-234.

3. Burrows B, Martinez FD, Halonen M, Barbee RA, Cline MG. Association of asthma with serum IgE levels and skin-test reactivity to allergens. N Engl J Med 1989; 320: 271-277.

4. Platts-Mills TAE, Thomas WR, Aalbarese RC, Vervloet D, Chapman MD. Dust mite allergens and asthma: report of a second international workshop. J Allergy Clin Immunol 1992; 89: 1046-1060.

5. Sporik R, Holgate ST, Platts-Mills TAE, Cogswell JJ. Exposure to house dust mite allergen (Der I P) and the development of asthma in childhood: a prospective study. $N$ Engl J Med 1990; 323: 502-507. 
6. Holt PG. A potential vaccine strategy for asthma and allied atopic diseases during early childhood. Lancet 1994; 344: 456-458.

7. Sigurs N, Bjarnason R, Sigurbergsson F, Kjellman B, Bjorksten B. Asthma and immunoglobulin E antibodies after respiratory syncitial virus bronchitis: a prospective cohort study with matched controls. Paediatrics 1995; 95: 500-505.

8. Martinez F. Role of viral infections in the inception of asthma and allergies during childhood: could they be protective? Thorax 1994; 49: 1189-1191.

9. Kogevinas M, Anto JM, Soriano JB, Tobías A, Burney $\mathrm{P}$, and the Spanish Group of the European Asthma Study. Am J Respir Crit Care Med 1996; 154: 137-143.

10. Jarvis D, Chinn S, Lucynska Ch, Burney P. Association of respiratory symptoms and lung function in young adults with use of domestic gas appliances. Lancet 1996; 347: 426-431.

11. Silverman M. Out of the mouths of babes and sucklings: lessons from early childhood asthma. Thorax 1993; 48: 1200-1204.

12. Busse W, Banks-schlegel P, Larsen G. Childhood versus adult-onset asthma. Am J Respir Crit Care Med 1995; 151: 1635-1639.

13. Burney PGJ, Luczynska C, Chinn S, Jarvis D, for the European Community Respiratory Health Survey. The European Community Respiratory Health Survey. Eur Respir J 1994; 7: 954-960.

14. Samet JM. Epidemiological approaches for the identification of asthma. Chest 1987; 91: Suppl. 6, 74S-78S.

15. Toelle BG, Peat JK, Salome CM, Mellis CM, Woolcock AJ. Toward a definition of asthma for epidemiology. Am Rev Respir Dis 1992; 146: 633-637.

16. Cox DR, Snell EJ. Analysis of binary data, 2nd ed. London, Chapman \& Hall, 1989.

17. Brunekreef B, Groot B, Hoek G. Pets, allergy and respiratory symptoms in children. Int J Epidemiol 1992; 21: $338-342$.

18. Grupo español del estudio europeo del asma. Estudio europeo del asma. Prevalencia de sintomas relacionados con el asm en cinco áreas españolas. Med Clin 1995; 104: 486-492.

19. Readline S. Challenges in interpreting gender differences in asthma. Am J Respir Crit Care Med 1994; 150: 1219-1221.

20. Chinn S, Zannolin E, Lai E, Jarvis D, Luczynska CM,
Burney PGJ. Adjustment of reported prevalence of respiratory symptoms for non-response in a multi-centre health study. Int J Epidemiol 1995; 24: 603-611.

21. Peat JK, Salome CM, Woolcock AJ. Longitudinal changes in atopy during a 4-year period: relation to bronchial responsiveness and respiratory symptoms in a population sample of Australian schoolchildren. J Allergy Clin Immunol 1990; 85: 65-74.

22. Sears MR, Herbison GP, Holdaway MD, Hewitt CJ, Flannery EM, Silva PA. The relative risks of sensitivity to grass pollen, house dust mite and cat dander in the development of childhood asthma. Clin Exp Allergy 1989; 19: 419-424.

23. Pollart SM, Chapman MD, Fiocco GP, Rose G, PlattsMills TAE. Epidemiology of acute asthma: IgE antibodies to common inhalant allergens as a risk factor for emergency room visits. J Allergy Clin Immunol 1989; 88: 875-882.

24. Suphioglu C, Singh M, Taylor P, et al. Mechanism of grass pollen-induced asthma. Lancet 1992; 339: 569-572.

25. Soriano JB, Tobías A, Kogevinas M, Sunyer J, Sáez M, Martínez-Moratalla $\mathrm{J}$, et al. Atopy and non-specific bronchial responsiveness. A population based study. Am J Respir Crit Care Med 1996; 154: 1636-1640.

26. Crane J, Pearce N, Shaw R, Fitzharris P, Mayes C. Asthma and having siblings. Br Med J 1994; 309: 272.

27. Strachan DP, Hay fever, hygiene and household size. Br Med J 1989; 299: 1259-1260.

28. Lewis S, Richards D, Bynner J, Butler N, Britton J. Prospective study of risk factors for early and persistent wheezing in childhood. Eur Respir J 1995; 8: 349_ 356.

29. Von Mutius E, Martinez F, Fritzsch C, et al. Skin test reactivity and number of siblings. Br Med $J$ 1994; 308: 692-695.

30. Gelber LE, Seltzer LH, Bouzakis JK, Platts-Mills SM. Sensitization and exposure to indoor allergens as risk factors for asthma among patients presenting to hospital. Am Rev Respir Dis 1993; 147: 573-578.

31. Von Mutius E, Illi S, Nicolai T, Martinez FD. Relation of indoor heating with asthma, allergic sensitization, and bronchial responsiveness: survey of children in South Bavaria. Br Med J 1996; 312: 1448-1450.

32. Shirakawa T, Enomoto T, Shimazu Sh, Hopkin JM. The inverse association between tuberculin responses and atopic disorder. Science 1997; 275: 77-79. 